\title{
Programa Bolsa Família como estrategia de diversificação dos meios de vida rurais: uma experiência no sul de Minas Gerais
}

\author{
Program Bolsa Familia as a strategy for diversification of rural livelihoods: an \\ experience in the south of Minas Gerais \\ Marina Vilela Brandão Leite Faria ${ }^{1}$ (1), Maria Izabel Vieira Botelho ${ }^{1}$ (1), Edson Arlindo Silva ${ }^{2}$ (1) \\ ${ }^{1}$ Universidade Federal de Vicosa (UFV), Vicosa (MG), Brasil. E-mails: milefolium@yahoo.com.br; mbotelho@ufv.br \\ ${ }^{2}$ Universidade Federal de Uberlândia (UFU), Uberlândia (MG), Brasil. E-mail: edsonasilva@ufu.br
}

\begin{abstract}
Como citar: Faria, M. V. B. L., Botelho, M. I. V., \& Silva, E. A. (2020). Programa Bolsa Família como estrategia de diversificação dos meios de vida rurais: uma experiência no sul de Minas Gerais. Revista de Economia e Sociologia Rural, 58(3), e159635. https://doi.org/10.1590/1806-9479.2020.159635
\end{abstract}

Resumo: O Programa Bolsa Família é uma política pública social que pode ser acessada tanto pela população rural quanto urbana. O objetivo deste estudo foi refletir em que medida o acesso a este programa, adotado para combate à pobreza, pode representar um fator estruturante de possibilidades de estratégias de diversificação dos meios de vida. Trata-se de uma pesquisa qualitativa, que utilizou como fontes de informação a revisão bibliográfica e a análise documental, bem como entrevistas semiestruturadas realizadas com representantes de organizações e com representantes de unidades familiares beneficiadas da zona rural do município de Luminárias, estado de Minas Gerais. A partir do acesso ao programa, verificou-se a manutenção de aspectos relacionados à vida digna, viabilizados principalmente por meio do consumo e da minimização de vulnerabilidades e privações, principalmente das mulheres. Estes são aspectos fundamentais para superação da pobreza e para viabilização de estratégias de diversificação dos meios de vida. O estudo sugere outras reflexões relacionadas a fatores estruturantes de diversificação dos meios de vida, como: o modelo de desenvolvimento rural, relações entre o rural e o urbano e a qualidade dos serviços acessados por meio das condicionalidades do programa.

Palavras-chave: Programa Bolsa Família, meios de vida, políticas públicas.

\begin{abstract}
The Bolsa Família program is a public social policy that can be accessed by both rural and urban populations. The objective of this study was to reflect to which extent access to this program that was adopted to combat poverty, may represent a structuring factor of possibilities for livelihood diversification strategies. It is a qualitative research that used bibliographic review, documentary analysis, as well as semi-structured interviews with representatives of organizations and with representatives of family units benefiting from the rural area of the municipality of Luminárias, state of Minas Gerais. From the access to the Program, it was verified the maintenance of aspects related to the dignified life, made feasible mainly through the consumption and the minimization of vulnerabilities and deprivations, mainly of the women. These are fundamental aspects for overcoming poverty and for enabling diversification strategies for livelihoods. The study suggests other reflections related to structuring factors of livelihood diversification, such as the rural development model, rural-urban relations, and the quality of the services accessed through the program's conditionalities.
\end{abstract}

Keywords: Bolsa Familia Program, livelihoods, public policies. 


\section{INTRODUÇÃO}

Políticas sociais estão diretamente relacionadas com direitos sociais ${ }^{1}$, como saúde, educação, alimentação e assistência social, dentre outras modalidades. Assim, o Programa Bolsa Família, busca contribuir para a solução de problemas sociais relacionados à pobreza e à insegurança alimentar, conciliando a transferência de renda com o acesso a serviços como os de saúde e educação e ações relacionadas à assistência social.

Este programa tem sido amplamente estudado a partir de diferentes abordagens (análises qualitativas, quantitativas, estudos de caso, etc.) e com diferentes recortes. Parte destes estudos enfatiza os resultados e impactos do programa e sua contribuição para o alívio da fome e da pobreza. Alguns estudos abordam os efeitos do programa no que diz respeito à realização das condicionalidades e ações complementares (Craveiro \& Ximenes, 2013; Santos \& Magalhães, 2012). Outros refletem sobre o desenho institucional, visão geral e trajetória do programa, problematizando de que maneira o desenho atual contribui para uma visão integrada da pobreza (Paiva et al., 2013; Campello, 2013; Soares \& Sátyro, 2009). Algumas análises refletem ainda sobre os efeitos do programa relacionados aos seus objetivos básicos, a partir de contextos mais gerais (Neder et al., 2015; Jannuzzi \& Pinto, 2013; Sant'Ana, 2014) ou a partir de contextos específicos, como municípios ou regiões (Pires \& Jardim, 2014; Castilho e Silva, 2014). Destacam-se ainda estudos que tratam de efeitos mais indiretos do Programa Bolsa Família, como a sua capacidade de contribuir para o desenvolvimento rural e local e para a melhoria da qualidade de vida (Castilho e Silva \& Schneider, 2015; Lui \& Molina, 2013; Barbosa \& Paulo, 2012), empoderamento e mobilidade social das mulheres, autonomia e equidade de gênero (Rego \& Pinzani, 2013; Leroy et al., 2014; Morton, 2013), correlação entre a organização do trabalho familiar e o acesso a políticas públicas (Mota et al., 2014) ou, ainda, as dimensões políticas e o modelo de investimento social relacionados ao Programa Bolsa Família (Hall, 2008, 2012).

Trata-se de uma política social de transferência condicionada de renda e, segundo dados oficiais dos formuladores do programa, as transferências de renda objetivam o alívio imediato da pobreza possibilitando o consumo de bens e as condicionalidades, relacionadas à área de saúde e educação, podem ser compreendidas como uma forma de romper o ciclo de pobreza entre gerações, reconhecendo que o alcance dos direitos sociais são elementos fundamentais para a superação da pobreza e garantindo proteção social aos grupos vulneráveis. Pretende-se com este modelo combater a fome e a pobreza e estimular a emancipação sustentada das famílias que vivem em situação de pobreza e extrema pobreza no país (Brasil, 2004).

Vale destacar que o Programa pode ser acessado pela população pobre e extremamente pobre ${ }^{2}$ da zona urbana e da zona rural ${ }^{3}$; contudo, ressalta-se que, embora a população rural também possa acessar, trata-se de uma política pública que não tem foco direto no rural, sendo antes considerada como uma política que garante um mínimo relacionado aos direitos sociais e que, a partir desta garantia, pode estimular o acesso a outras políticas.

Segundo Grisa \& Schneider (2014), a partir de 1997-98, as políticas para a agricultura familiar começaram a compreender ações assistenciais e sociais, iniciadas com o Programa Comunidade Solidária e, posteriormente, o Programa Fome Zero, no qual se destacou o Bolsa Família. De 1998 até meados de 2000 "emergiu um conjunto de ações de transferência de renda que contemplaram a agricultura familiar (ainda que não exclusivamente), como o Bolsa Escola, Bolsa Alimentação e Auxílio Gás, que a partir de 2003 foram integradas ao Bolsa

\footnotetext{
${ }^{1}$ Enquanto o pilar dos direitos civis e políticos é a liberdade (de expressão, de associação, de religião, de pensamento, direito à propriedade privada e de participar da vida política), para os direitos sociais o pilar é a igualdade e a exigência de que o Estado proporcione as precondições essenciais ao exercício da cidadania, promovendo a integração do indivíduo à sociedade. Assim, os direitos sociais buscam corrigir os desequilíbrios causados pelas ações individuais no âmbito do mercado, de modo a garantir que todos tenham acesso a uma vida saudável e autônoma (Mesquita, 2007, p. 33).

2Para efeito da execução Programa Bolsa Família, no período analisado pelo estudo, é considerado pobre aquele indivíduo que vive com renda de $R \$ 77,00$ até $R \$ 154,00$ e extremamente pobre aquele indivíduo que vive com até $\mathrm{R} \$ 77,00$ mensais (Brasil, 2004).

${ }^{3} O$ estudo de Castilho e Silva \& Schneider (2015) apresenta dados da Secretaria de Avaliação e Gestão da Informação (SAGI/CECAD) de 2014, que apontam que 28,67\% dos domicílios que recebiam o Programa Bolsa Família em todo o Brasil estavam localizados na zona rural e $71,29 \%$ estavam na zona urbana.
} 
Família" . Os autores afirmam que ações sociais foram reforçadas pela criação do programa Brasil Sem Miséria, que contempla o Programa Bolsa Família e ações para inclusão social e produtiva para a população rural, por intermédio de fomento a fundo perdido para aquisição de insumos e equipamentos, assistência técnica diferenciada para este público e doação de sementes e tecnologias da Embrapa para iniciar os processos produtivos. Grisa \& Schneider (2015) afirmam que a existência de políticas sociais com alcance das populações rurais, nos moldes do Programa Bolsa Família, contribui para o reconhecimento do espaço rural como espaço de vida e trabalho, na medida em que possibilitam sua permanência e manutenção neste espaço com algum nível de qualidade.

A abordagem de meios de vida, utilizada como ferramenta analítica neste artigo, implica na apreensão de vários elementos constitutivos da vida social, como os recursos sociais, físicos, humanos, financeiros e naturais, destacados por Ellis (1999). As estratégias de diversificação dos meios de vida pressupõem a articulação de alguns destes recursos por parte das unidades familiares analisadas, como forma de melhorar ou manter determinados padrões de qualidade, no sentido da superação da pobreza. Segundo Ellis (1998), a estratégia de diversificação melhora a segurança dos meios de vida e amplia as possibilidades das unidades familiares (Ellis, 1998, p. 29) ${ }^{4}$. Em relação aos meios de vida da população rural, segundo Perondi \& Schneider (2012, p. 118), o seu fortalecimento consiste na criação de estratégias variadas de trabalho e renda que favoreçam a resiliência em choques, crises e vulnerabilidades, o que pode incluir o acesso às transferências sociais.

O acesso ao Programa Bolsa Família pode representar, portanto, uma possibilidade de diversificação e fortalecimento dos meios de vida. Considerando esta possibilidade, existe a necessidade de reflexão sobre as formas com que o Programa pode contribuir para a redefinição dos recursos que compõem os meios de vida que, por sua vez, apresenta relação com recursos disponíveis, processos institucionais e estruturas organizacionais, composição familiar, dentre outros. Pretendeu-se refletir, a partir do referencial teórico utilizado, dos dados de pesquisa e da análise de outros estudos, em que medida o acesso ao Programa Bolsa Família pode representar um fator estruturante de possibilidades de diversificação dos meios de vida, com vistas à melhoria das condições de vida e superação da pobreza.

\section{METODOLOGIA}

Este estudo foi conduzido no município de Luminárias, situado na macrorregião do Sul de Minas Gerais (Instituto Brasileiro de Geografia e Estatística, 2010). Segundo dados do Instituto Brasileiro de Geografia e Estatística (2010), em 2010 o município possuía 5422 habitantes, sendo que 1256 residiam na área rural (aproximadamente 23\% da população) e 4166 residiam na área urbana ou sede do município (o que representa aproximadamente $77 \%$ da população total), onde se localizam o comércio local, a sede da prefeitura, correios, casa lotérica, Centro de Referência em Assistência Social (CRAS), escolas, posto de saúde, dentre outros serviços à população. De acordo com observações do trabalho de campo, a população rural do município encontrava-se dispersa de maneira irregular, com a presença de aglomerados de domicílios em determinados locais.

Além da atividade de ecoturismo, crescente no município, outras atividades econômicas importantes tanto na participação do PIB municipal quanto no fornecimento de empregos formais foram: agropecuária, serviços e indústria (extrativa mineral, de pedras decorativas) (Brasil, 2015). Segundo dados do Atlas de Desenvolvimento Humano no Brasil, em 2010, das pessoas ocupadas na faixa etária de 18 anos ou mais do município, 37,45\% trabalhavam no setor agropecuário, $12,01 \%$ na indústria extrativa, 3,07\% na indústria de transformação, $6,46 \%$ no setor de construção, $0,76 \%$ nos setores de utilidade pública, $13,94 \%$ no comércio e $25,25 \%$ no setor de serviços. Estes dados demonstram a importância do rural para o município.

\footnotetext{
${ }^{4}$ Extraído do original "A second conclusion is that sheer capability to diversify income sources signifies an improvement in the livelihood security and income-increasing capabilities of the rural household. Therefore, policies that reduce constraints to diversification and widen its possibilities are in general desirable [...]. Finally, there is a need for more systematic knowledge of livelihood strategies and their links to macroeconomic policies" (Ellis, 1998, p. 29).
} 
Segundo o Instituto Brasileiro de Geografia e Estatística (2006), a partir dos dados do censo agropecuário de 2006, Luminárias possuía 280 estabelecimentos agropecuários, na condição de produtores. Contemplavam arrendatários, proprietários, meeiros, ocupantes ou produtores sem área; portanto, agricultores nas mais diversas situações, o que ressalta a heterogeneidade da população rural local. As informações coletadas durante a pesquisa de campo apontam que os agricultores familiares do município comercializavam principalmente a sua produção de leite e café, em cooperativas e laticínios locais ou da região. O Programa Nacional de Alimentação Escolar (PNAE) e uma feira livre municipal para agricultores funcionavam no município no período em que as pesquisas foram realizadas; contudo, o Programa de Aquisição de Alimentos (PAA) funcionou ente 2010 e 2012, mas foi interrompido em função de questões relacionadas à gestão municipal do programa.

Segundo relatórios do Ministério do Desenvolvimento Social e Combate à Fome (MDS), em junho de 2014, 928 famílias estavam inscritas no Cadastro Único para Programas Sociais (CadÚnico) $^{5}$; em setembro de 2014, período próximo à realização das entrevistas que compõem a base de informações deste estudo, eram 382 famílias beneficiadas pelo PBF no município, cujo valor médio repassado era de $R \$ 140,20$ (Brasil, 2014). Os dados de campo apontam que o Programa Bolsa Família beneficiou aproximadamente 81 famílias na zona rural do município no período considerado.

As entrevistas foram realizadas em unidades familiares beneficiadas, residentes na zona rural, selecionadas aleatoriamente e segundo a disponibilidade das famílias para a participação. Assim, foram realizadas entrevistas em 16 unidades familiares e com representantes de três organizações relacionadas ao Programa Bolsa Família no município e à zona rural, entre outubro e dezembro de 2014. As entrevistas apontaram que os benefícios foram retirados na casa lotérica da cidade, mensalmente, por meio da utilização do cartão do Programa e a média dos valores recebidos, declarados nas entrevistas, foi de $R \$ 128,85$.

Este foi um estudo de caso, de natureza qualitativa. Utilizou-se para o levantamento de dados, pesquisa bibliográfica e documental e entrevistas semiestruturadas. Buscou-se, a partir da coleta de dados, entender os seguintes aspectos relacionados aos meios de vida e ao programa analisado: composição e caracterização geral das unidades familiares, composição do grupo doméstico, forma de participação no Programa Bolsa Família, utilização dos recursos acessados, a percepção dos beneficiados em relação ao programa e as principais mudanças observadas a partir do acesso ao programa. Vale destacar que as entrevistas estão sujeitas à parcialidade e à imprecisão de fatos, já que recorrem à memória e percepção dos entrevistados, o que foi minimizado a partir de cruzamento com as outras fontes de dados utilizadas.

As reflexões relativas à capacidade do Programa Bolsa Família de se tornar um fator estruturante para novas possibilidades de diversificação dos meios de vida para os beneficiados foram realizadas à luz dos referenciais teóricos de meios de vida utilizados, analisando-se as transformações no tempo a partir da memória e da percepção dos beneficiados. Este estudo recebeu aprovação do Comitê de Ética em Pesquisa com Seres Humanos (CEP) da Universidade Federal de Viçosa.

\section{REFERENCIAL TEÓRICO}

Para Pereira (2009) desde o surgimento do termo "política" entende-se que ela se dá pela convivência entre os diferentes (em idade, sexo, cor e outras características), bem como entre os desiguais, se considerarmos a estrutura social (de classe e status). Este fato revela seu caráter conflituoso, mas também pode proporcionar contra poderes e, em última análise, tem potencial para amadurecer a cidadania (Pereira, 2009). Segundo a autora, a política compõe-se de atividades formais (regras estabelecidas) e atividades informais (negociações e diálogos) que são destinadas a resolver, sem violência, conflitos envolvendo bens e assuntos públicos para a coexistência em sociedade.

\footnotetext{
5É importante destacar que nem todas as famílias cadastradas no CadÚnico estão aptas a receber os benefícios do Programa Bolsa Família (PBF), em função dos níveis de renda. Assim, o cadastro é realizado com famílias que possuem renda superior ao limite superior atendido pelo Programa Bolsa Família.
} 
Secchi (2010) define as políticas públicas como diretrizes para solucionar um problema público ou coletivamente relevante. Segundo Jesus (2011), o termo "política" nas Ciências Sociais pode significar o estudo do poder. Contudo, quando aplicado às políticas específicas, está se referindo a estratégias de governo que vinculam planos, projetos e programas aplicados em determinadas áreas com suas diretrizes específicas (Jesus, 2011, p.33).

A política social pode se organizar para alcançar tanto a cobertura de riscos sociais quanto buscar oportunidades, enfrentar situações de pobreza, combater as desigualdades sociais e melhorar as condições de vida da população (Jesus, 2011, p.35). Quanto a estas políticas específicas, Höfling (2001, p. 31) as define como "[...] ações que determinam o padrão de proteção social adotado pelo Estado voltadas, em princípio, para a redistribuição dos benefícios sociais, visando diminuição das desigualdades estruturais produzidas pelo desenvolvimento socioeconômico".

Segundo o exposto, as políticas sociais estariam associadas aos direitos sociais ${ }^{6}$ e à distribuição dos benefícios sociais, o que é, notadamente, um problema público. Embora o acesso ao Programa Bolsa Família não seja um direito constitucional, lida direta e indiretamente com os direitos sociais contemplados na Constituição brasileira, seja por possibilitar o acesso a alguns bens e serviços proporcionados por meio da renda transferida, seja por estimular o acesso a serviços de saúde e educação prestados pelo Estado como condicionalidades.

O Programa Bolsa Família (PBF) é vinculado à Secretaria Nacional de Renda de Cidadania (SENARC), do Ministério do Desenvolvimento Social e Combate à Fome (MDS). Foi criado em 20 de outubro de 2003 pela Medida Provisória no 132, sancionado em nove de janeiro de 2004 pela Lei $n^{\circ} 10836$ e regulamentado em dezessete de setembro de 2004 pelo Decreto $n^{\circ} 5209$. Segundo Craveiro \& Ximenes (2013), o Programa Bolsa Família, em dois de junho de 2011, por força do Decreto $n^{\circ} 7942$, passou a integrar o Plano Brasil Sem Miséria. O Plano Brasil Sem Miséria possui, além da perspectiva de garantia de renda, a de acesso a serviços e inclusão produtiva. Portanto, algumas transformações vêm ocorrendo no âmbito do Programa Bolsa Família, visando superação da extrema pobreza no país, e sua trajetória contribuiu para a emergência do Plano Brasil Sem Miséria (Paiva et al., 2013, p. 43).

Em relação às características gerais do Programa Bolsa Família, segundo alteração dada pelo decreto 6392/08, a concessão dos benefícios tem caráter temporário, em que as unidades familiares beneficiárias devem respeitar a elegibilidade, revista a cada dois anos (Brasil, 2004). Portanto, não há um limite temporal previamente estabelecido para permanência no programa, desde que se cumpram as exigências estabelecidas na legislação.

Trata-se de um programa de transferência de renda condicionada, cujas condicionalidades são contrapartidas realizadas pelas famílias para a obtenção do benefício e envolvem frequência escolar mensal mínima (de $85 \%$, para crianças e adolescentes de seis a quinze anos e de $75 \%$ para jovens de dezesseis e dezessete anos), acompanhada pelo Ministério da Educação, e também atualização de questões relacionadas à saúde (como vigilância alimentar e nutricional e vacinação para crianças menores de sete anos, acompanhamento de saúde e exame pré-natal para gestantes), fiscalizadas pelo Ministério da Saúde (Brasil, 2004).

O Programa Bolsa Família inova em diversos aspectos em sua gestão e execução, uma vez que articula diversos setores do governo (assistência social, saúde e educação), diversas esferas da Federação (estruturas do governo federal e agentes locais) e diversas frentes de trabalho para superação da pobreza (como as transferências monetárias e oportunidades de capacitação para inserção produtiva) (Paiva et al., 2013, p. 38). O programa disponibiliza uma

\footnotetext{
6Segundo a Constituição Federal de 1988: "Art. 6 São direitos sociais a educação, a saúde, a alimentação, o trabalho, a moradia, o lazer, a segurança, a previdência social, a proteção à maternidade e à infância, a assistência aos desamparados, na forma desta Constituição" (Brasil, 1988). A Emenda Constitucional n 64, de 2010, incluiu a alimentação como direto constitucional.
} 
variedade de modalidades de benefícios ${ }^{7}$, que diferem de acordo com a renda e a composição familiar e destinam-se a pobres e extremamente pobres.

$\mathrm{O}$ acesso aos benefícios, bem como o cumprimento das suas condicionalidades têm potencial para incidir sobre os diferentes elementos dos meios de vida dos beneficiados, com vistas à superação da condição de pobreza e melhoria das condições de vida. Para Campello (2013), o programa contribui para a inclusão social de milhões de famílias brasileiras pobres e extremamente pobres por intermédio do alívio imediato da situação de pobreza e também contribui para o acompanhamento dos beneficiados pelos serviços de saúde e educação.

Sen (2000) afirma que o desenvolvimento e a superação da pobreza dependem da expansão de liberdades e aponta cinco liberdades que se ligam umas às outras, contribuindo para o aumento da liberdade humana em geral, que, por sua vez, é o objetivo do desenvolvimento. Para o alcance destas liberdades, contudo, é importante e necessária a expansão das capacidades das pessoas de levar o tipo de vida que valorizam. $O$ autor alerta para a necessidade de que a pobreza seja entendida como privação das capacidades individuais, pobreza das vidas e liberdades humanas e não apenas como baixa renda. Portanto, as liberdades incluem capacidades elementares para evitar as diversas formas de privações. Segundo Sen (2000) o desenvolvimento deve ser entendido como o processo onde os indivíduos dispõem de meios para alcançar o que valorizam e ampliar a sua capacidade de escolha.

O conceito de meios de vida tem sido utilizado como a tradução para livelihoods, que, grosso modo, contempla as capacidades das pessoas e as estratégias utilizadas por elas em contextos de adversidades, demonstrando como indivíduos podem ser hábeis para sobreviver nestes contextos (Perondi \& Schneider, 2012, p. 120). A abordagem de meios de vida é uma ferramenta analítica que busca entender como as pessoas fazem para sobreviver em contextos de adversidades sociais, econômicas e ambientais; além disto, ela tem sido amplamente utilizada em estudos sobre a pobreza rural no mundo, especialmente no continente africano (Perondi \& Schneider, 2012, p. 118). Esta abordagem dá suporte para a investigação das capacidades que orientam as estratégias das pessoas para sua sobrevivência e melhoria do padrão de vida em determinados contextos.

Neste sentido, diferentes autores trouxeram importantes contribuições para a utilização das abordagens de meios de vida, incorporadas em maior ou menor medida por agências internacionais de desenvolvimento e institutos de pesquisa. Destaca-se a contribuição de Frank Ellis, que priorizou o debate sobre "diversificação dos meios de vida", estudando principalmente a realidade de países da África subsaariana.

Segundo Perondi \& Schneider (2012, p. 118), esta abordagem foi difundida em meados dos anos de 1990, inicialmente na Inglaterra e se disseminou na última década para além das fronteiras europeias, fundamentando estudos sobre a realidade rural em países pobres. Segundo Perondi \& Schneider (2012, p. 120), Chambers e Conway foram pioneiros na utilização do conceito de "meios de vida sustentáveis".

Niederle \& Grisa (2008, p. 47) apontam que, ainda que de modo impreciso, a discussão sobre meios de vida apresenta um diálogo com a abordagem de Amartya Sen, sobretudo quando enfatiza a questão dos ativos e das capacidades (capabilities) dos atores sociais como elementos fundamentais para o desenvolvimento e superação de adversidades. Esta relação entre a abordagem de meios de vida e a abordagem de Sen sobre pobreza e desenvolvimento também foi apontada por Perondi \& Schneider (2012).

\footnotetext{
${ }^{7}$ Segundo alterações do Decreto 8232/14 passou a vigorar os seguintes valores de benefícios ativos: benefício básico, no valor de $R \$ 77,00$, destinado às unidades familiares que se encontrem em situação de extrema pobreza, independente da sua composição; o benefício variável, no valor de $R \$ 35,00$, destinado àquelas unidades familiares pobres e extremamente pobres que tenham em sua composição, gestantes, nutrizes, crianças de 0 a 12 anos ou adolescentes de até 15 anos (as unidades familiares podem receber até 5 benefícios variáveis de acordo com o número de filhos); o benefício variável vinculado ao adolescente, no valor de $R \$ 42,00$, destinado às unidades familiares pobres ou extremamente pobres que tenham em sua composição adolescentes com idade entre 16 e 17 anos (as unidades familiares podem receber até 2 benefícios variáveis vinculados ao adolescente) e o benefício para superação da extrema pobreza, cujo valor será calculado a partir da diferença entre $R \$ 77,01$ e a soma da renda familiar mensal e dos benefícios financeiros, dividida entre os integrantes da unidade familiar (Brasil, 2004). Estes eram os valores vigentes no período de realização da pesquisa.
} 
Assim, no que se refere à utilização da abordagem de meios de vida, para tratar da análise do Programa Bolsa Família, que visa, dentre outras coisas, minimizar a pobreza por intermédio de estratégias mediadas pelo Estado, entende-se que o acesso ao referido programa pode influenciar as capacidades presentes e futuras das pessoas. Ademais, o acesso das famílias ao programa, que disponibiliza e fortalece recursos materiais e sociais poderá contribuir para o redesenho dos elementos constitutivos de seus meios de vida, o que pode significar a manutenção e mesmo a melhoria da qualidade de vida. Desta forma, o acesso pode gerar novas possibilidades de diversificação dos meios de vida.

Para Niederle \& Grisa (2008, p. 65), é importante considerar que o desenvolvimento está relacionado às capacidades e oportunidades de acesso e manutenção dos ativos de capitais e, concomitantemente, à criação de um ambiente social, político e econômico que favoreça oportunidades mais justas.

Os meios de vida envolvem diversos elementos, que estão distribuídos nos denominados recursos/ativos/capitais. Segundo Ellis (1999), diferentes pesquisadores como Carney e Scoones, preocupados com pobreza, sustentabilidade e meios de vida, que trabalharam com o chamado quadro de meios de vida sustentáveis, apontam os seguintes recursos dos meios de vida: natural, físico, financeiro, humano e social Destaca-se a seguinte definição:

Meios de vida englobam renda, em dinheiro ou em espécie, bem como as instituições sociais (parentes, familiares e assim por diante), relações de gênero, e os direitos de propriedade necessários para apoiar e sustentar um determinado padrão de vida (Ellis, 1998$, p. 6$)^{8}$

Em relação às estratégias de meios de vida, Niederle \& Grisa (2008, p. 49) apontam que são projetos específicos que dependem tanto da capacidade dos agentes (posse de ativos), quanto da estrutura de oportunidades (condições atribuídas ao contexto onde os agentes estão inseridos). Na mesma linha, Ellis (1999) afirma que as estratégias de meios de vida são compostas por uma série de atividades que são mediadas por fatores sociais (relações sociais, instituições, organizações) e por tendências exógenas (por exemplo, as tendências econômicas) e choques (seca, doenças, inundações, pragas) ${ }^{9}$.

O reconhecimento do acesso ao Programa Bolsa Família como uma estratégia temporária empreendida pelos membros das unidades familiares, capaz de dar suporte à diversificação dos meios de vida, pode ser respaldado na afirmação de Ellis (1998, p. 4) que, ao examinar outros estudos, define que os meios de vida também podem incluir acessos derivados a serviços sociais e públicos prestados pelo Estado.

A diversificação dos meios de vida “[...] é entendida como o processo pelo qual famílias rurais constroem um portfólio diversificado de atividades e capacidades de apoio social visando sobrevivência ou a melhoraria dos padrões de vida" (Ellis, 1998, p. 4, tradução dos autores $)^{10}$. Para o autor, "as causas e consequências da diversificação são diferenciadas, na prática, por localização, ativos, renda, oportunidades e relações sociais" (Ellis, 1998, p. 3, tradução dos autores) ${ }^{11}$. Afirma ainda que indivíduos e unidades familiares possuem diferentes potenciais de acesso às fontes de renda e a participação destas fontes terá também diferentes impactos sobre a pobreza em cada situação. Isso implica em afirmar que a capacidade de diversificação dos meios de vida e de renda varia entre indivíduos nas unidades familiares, entre unidades familiares e nos diferentes momentos e contextos.

${ }^{8}$ Extraído do original "A livelihood encompasses income, both cash and in kind, as well as the social institutions (kin, family, compound, village and so on), gender relations, and property rights required to support and to sustain a given standard of living" (Ellis, 1998, p. 4).

'Extraído do original: "In pursuing livelihood strategies composed of a range of activities, both the access to assets and the use to which they can be put are mediated by social factors (social relations, institutions, organizations) and by exogenous trends (e.g. economic trends) and shocks (drought, disease, floods, pests)" (Ellis, 1999).

${ }^{10}$ Extraído do original "In this article livelihood diversification is defined as the process by which rural families construct a diverse portfolio of activities and social support capabilities in their struggle for survival and in order to improve their standards of living" (Ellis, 1998, p. 4).

${ }^{11}$ Extraído do original: "[...] the causes and consequences of diversification are differentiated in practice by location, assets, income, opportunity and social relations [...] (Ellis, 1998, p. 3). 
Neste sentido, é importante destacar, como característica central da diversificação dos meios de vida, as variedades de possíveis fontes de renda como: agrícolas, não agrícolas, remessas (financeiras ou não, provenientes daqueles que se encontram fora das unidades familiares) e as transferências sociais. Segundo Ellis (1998), o processo de diversificação pode ser resultado de uma série de determinantes, como a sazonalidade, a gestão de risco, o enfrentamento de crise, a composição do grupo doméstico, o mercado de trabalho etc., que podem ser moldados de acordo com a interação com o ambiente físico ou mudanças na economia mais ampla (Ellis, 1998, p. 16). Ellis (1999, p.2) afirma que "a diversidade de meios de vida resulta em complexas interações com a pobreza, distribuição de renda, a produtividade agrícola, conservação ambiental e de relações de gênero [...]" e que a natureza destas interações precisa ser compreendida pelas políticas de redução de pobreza rural ${ }^{12}$.

\section{RESULTADOS E DISCUSSÃO}

As estratégias dos meios de vida são construídas de acordo com o portfólio de recursos disponíveis nas unidades familiares. Estes recursos estão relacionados com as oportunidades e capacidades dos indivíduos e grupos familiares que, por sua vez, interagem diretamente com as especificidades da composição familiar, como características de gênero e geração. Estas características determinam a capacidade de produção e consumo de cada indivíduo na unidade e, portanto, as possibilidades da unidade familiar de diversificação de meios de vida e renda nos diferentes contextos. Segundo Mota et al. (2014, p. 190) "estudos sobre o trabalho familiar no espaço rural têm enfatizado a divisão sexual sob influência da idade e geração e as diferenciações sociais daí decorrentes [...]".

No tocante aos recursos dos meios de vida das unidades familiares beneficiadas e sua relação com a estratégia de acesso ao programa, constatou-se, por meio desta pesquisa, que a partir dos recursos sociais já existentes nas unidades familiares, como as formas de sociabilidade (na escola ou por meio do serviço de assistência social), foi possível aos entrevistados o acesso a informações sobre o Programa Bolsa Família e o cadastro para o recebimento do benefício. Esta realidade verificada no estudo dialoga com a afirmação de Niederle \& Grisa (2008, p. 55) de que, para aqueles indivíduos e grupos com uma plataforma restrita de outros capitais, o capital social pode constituir uma oportunidade de acesso a outros capitais.

Segundo Niederle \& Grisa (2008, p. 53),

[...] os ativos compõem a base de recursos necessária à formação das alternativas de sobrevivência, as quais podem retroalimentar a plataforma de ativos. Não obstante, algumas estratégias podem sacrificar determinados ativos para garantir outros (sobreexploração dos recursos naturais para garantir recursos financeiros, por exemplo).

Vale ressaltar que os serviços gerais voltados para a população, relacionados às condicionalidades do programa ou não, concentram-se principalmente na zona urbana, sede do município analisado, e que a permanência dos beneficiados residentes na zona rural depende da mobilização de recursos para cumprir as condicionalidades na zona urbana e manter essa relação em maior ou menor intensidade e em diferentes graus de dependência.

Embora algumas unidades familiares visitadas estivessem mais distantes da sede municipal, não foi percebido isolamento delas, uma vez que havia disponibilidade de transporte escolar diariamente para as crianças e os jovens e, em algumas unidades, as famílias possuíam moto ou carro.

Considerando que os beneficiados entrevistados compreendiam as exigências e condicionalidades do programa - muitas vezes cumpridas desde os primeiros anos dos filhos - e considerando também a centralidade da sede do município no fornecimento de bens, serviços e ambiente de socialização, o acesso ao programa pode contribuir para o fortalecimento deste vínculo, atribuído direta (através das condicionalidades) ou

\footnotetext{
12Extraído do original: "[...]livelihood diversity results in complex interactions with poverty, income distribution, farm productivity, environmental conservation and gender relations that are not straightforward, are sometimes counterintuitive and can be contradictory between alternative pieces of case study evidence" (Ellis, 1999, p. 2).
} 
indiretamente (consumo no comércio local) ao programa. Portanto, percebeu-se que o Programa Bolsa Família, embora provavelmente não tenha inaugurado essa relação entre os entrevistados e a sede do município, contribuiu para o estreitamento das relações dos entrevistados com o ambiente urbano, oportunizando a retroalimentação da plataforma de recursos (sociais e outros), conforme afirma Niederle \& Grisa (2008), e contribuindo para fomentar novas possibilidades de diversificação.

Foi percebido a partir dos dados de pesquisa que a escola era um ambiente de convivência e sociabilidade para as crianças e os jovens e que ela é capaz de influenciar seus hábitos culturais e, por consequência, seus hábitos de consumo. Um relato da pesquisa de campo reflete a influência destas relações sociais no consumo: "[...] Por que ela tá indo na escola, como vou deixar minha filha ir toda suja e rasgada para a escola? Não tem como!" (ENTREVISTA 4). Destaca-se que a aquisição de material escolar, vestuário e calçados para as crianças e jovens foram relatados como gastos realizados a partir do acesso à renda transferida pelo Programa Bolsa Família.

Compreende-se que os indivíduos se relacionam com a sociedade e com outros indivíduos também por meio do consumo, nem sempre racionalizado. Considerar que o consumo é um processo de compartilhamento, público e coletivo, que constrói e mantém relações sociais é colocá-lo na sua perspectiva cultural. Isso revela o valor dos bens não em si próprios, mas no que representam, uma vez que podem contribuir de alguma maneira para a integração social, influenciando e redefinindo os recursos sociais.

É possível verificar que os recursos sociais e financeiros podem fortalecer vínculos sociais em determinados contextos. Nesta perspectiva, as transferências de renda do Programa Bolsa Família possibilitam, por meio da realização do consumo, o alcance das necessidades e alívio imediato da situação de pobreza e também o de integração social. Neste sentido, o acesso ao programa pode ser considerado um fator de contribuição de novas possibilidades de diversificação dos meios de vida.

Por outro lado, observou-se que o acesso a bens, como os alimentos, garantiu também melhores condições de vida, uma vez que havia a necessidade, de acordo com os entrevistados, de produtos obtidos em mercado local ou regional, incluindo alguns produtos alimentares. Percebeu-se a importância do acesso ao Programa Bolsa Família para esta garantia, expressos nos seguintes relatos: "Ajuda bem! Porque na roça a gente passa aperto" (ENTREVISTA 1), "Percebo que está me ajudando muito, né? (ENTREVISTA 13)"; "É um dinheirinho sagrado [...] é um dinheirinho que serve! (ENTREVISTA 15)"; "Pra gente que é pobre, é uma boa! As coisas da roça são muito difíceis, não dá muito dinheiro!" (ENTREVISTA 11); ou ainda "Ajuda bem! Se não fosse ele (o benefício recebido), não sei como ia fazer!" (ENTREVISTA 9).

Na pesquisa realizada, verificou-se a utilização dos recursos transferidos pelo programa como complementação da renda total destinada à compra de bens necessários à família (como óleo, arroz, feijão, trigo, macarrão, café e demais alimentos da cesta básica). Entre os gastos realizados, verificou-se ainda a aquisição de carnes e frutas (embora algumas famílias criassem galinhas e porcos e cultivassem algumas variedades de frutas).

Entende-se que a renda, em uma sociedade monetarizada, pode contribuir para a garantia do direito à vida digna e, consequentemente, pode proporcionar a base para se acionar outros direitos. Para Mesquita (2007, p.22), não há vida digna, respeito ou possibilidade do exercício das capacidades individuais e coletivas sem o alcance das necessidades humanas. Nesse sentido, a satisfação de bens materiais também é condição para a cidadania e para o gozo de outros direitos. Estas reflexões colocam o programa analisado em um patamar importante como fator estruturante de alternativas de diversificação dos meios de vida, uma vez que contribui para a garantia e/ou ampliação do acesso a bens necessários e manutenção da dignidade da vida dos beneficiados. Estas são condições fundamentais para qualquer ação no sentido da superação da pobreza e em favor do desenvolvimento.

A pesquisa de campo forneceu elementos para perceber a importância das rendas transferidas pelo Programa Bolsa Família no que se refere à oportunidade de renda regular, capaz de minimizar os efeitos da sazonalidade, expressos nos trabalhos temporários, principalmente em atividades agrícolas. Estas atividades laborais compõem as estratégias de 
meio de vida de algumas unidades familiares entrevistadas. As atividades giravam em torno de trabalhos temporários e permanentes em atividades agrícolas fora da unidade familiar, a venda de produtos agrícolas (como leite, café, doces e venda eventual de galinhas e porcos), aluguel de pasto e terreno, trabalhos em atividades não agrícolas (construção civil, trabalho em pedreira e faxina) e recebimento de benefício para pessoa com alguma deficiência na unidade familiar, além das transferências sociais atribuídas ao Programa Bolsa Família. As possibilidades de trabalhos realizados de maneira temporária ou mesmo a venda eventual de alguns produtos agrícolas provenientes da unidade familiar expressam uma frágil relação com o mercado de trabalho e são capazes de proporcionar tão somente uma renda sazonal e frequentemente insuficiente para a garantia de reprodução social destas famílias. Ademais, as atividades fora da propriedade, embora sejam uma opção de renda regular, com frequência retiram a capacidade produtiva das unidades familiares e, assim, diminuem sua capacidade de produção e obtenção de renda regular a partir da produção própria e sua comercialização.

Em uma entrevista realizada, registrou-se a limitação de demanda de trabalho local pelas grandes propriedades decorrente, segundo o relato, da baixa contratação de funcionários temporários, já que priorizavam alguns trabalhadores permanentes.

Vale refletir sobre a afirmação de Ellis (1999), para quem a diversificação dos meios de vida é capaz de minimizar os efeitos da sazonalidade de renda, expressa na diferença entre fluxos descontínuos de renda e demanda contínua de consumo, o que, para o referido autor, demonstra seu efeito positivo na medida em que permite a substituição de oportunidades que estão em declínio, por outras que estão em expansão. Ellis (1998) alerta sobre os riscos a que estão sujeitas todas as alternativas de fontes de renda agrícola, que são semelhantes entre si e diferentes em relação aos riscos relacionados à renda não agrícola. As diferentes alternativas de renda agrícola estão sujeitas, por exemplo, a fatores climáticos e econômicos, os quais não são os mesmos riscos associados à renda não agrícola e às transferências sociais.

Em relação a este ponto, a frequência e a segurança da renda acessada por meio do Bolsa Família foi um ponto positivo apontado pelos participantes desta pesquisa, conforme os seguintes relatos: "[...] aí já é um dinheirinho que todo mês você tira um tantinho lá e paga" (ENTREVISTA 3); "[...] fica contando com aquele dinheiro mês a mês. É um dinheiro mais certo que chega" (ENTREVISTA 4). Ademais, estabilidade mínima gerada pelo acesso ao Programa pode representar uma maior segurança para a manutenção dos padrões de vida e representa um fator estruturante para novas possibilidades de diversificação que, por sua vez, dependem também de outros elementos, como outras políticas, a economia geral, a estabilidade política, a oferta de postos de trabalho acessíveis, entre outras.

É importante que agentes e formuladores de políticas públicas realizem um planejamento de longo prazo capaz de integrar as ações de políticas complementares para desenvolvimento e superação da pobreza. Contudo, destaca-se que a regularidade de renda atribuída ao programa é capaz de gerar estabilidade e segurança para que, a partir de planejamento em prazo mais longo, seja possível a elaboração de possibilidades de integração entre políticas para o desenvolvimento e construção de melhores oportunidades para o público que atualmente é beneficiado pelo Programa Bolsa Família. Esse processo envolve os diversos atores, desde os beneficiados até os gestores, formuladores do programa, conselhos constituídos para seu acompanhamento, outros atores políticos e econômicos locais, entre outros.

Neste sentido, Anthony Hall (2008) alerta que, no que se refere à redução da pobreza, as transferências monetárias têm um impacto limitado em longo prazo porque são canalizadas para o consumo básico e não aumentam a capacidade de geração de renda. $O$ autor também reflete sobre o fato de que a política social pode ajudar a estimular o crescimento econômico e consolidar a democracia por meio da inclusão social de grupos mais pobres. Contudo, há um risco, dentre outros, de que as decisões e estratégias políticas priorizem respostas de curto prazo em detrimento de um planejamento de longo prazo que impulsione uma infraestrutura social básica, como educação, saúde e outros programas críticos de investimento do setor essenciais para o crescimento econômico e para o desenvolvimento social. 
A segurança de renda regular torna-se fundamental quando analisamos a situação das mulheres. Constatou-se no momento das entrevistas que em três casos as mulheres realizaram atividades remuneradas fora da unidade familiar (através da venda de doces, de serviços de faxina em casas vizinhas, colheita de café e venda eventual de galinhas). No período de realização das entrevistas, a maioria das mulheres não trabalhava fora da unidade familiar. Evidenciou-se que os trabalhos fora da unidade familiar representaram estratégias de renda regular, acessadas prioritariamente pelos homens. Todas eram responsáveis pelos trabalhos domésticos cotidianos e, em três casos, de cuidados com parentes (como irmão, tio, sobrinho). Destes últimos, em apenas um caso constatou-se remuneração. Participavam também da produção para o autoconsumo (horta, pomar e criação de galinhas e porcos) e, em alguns casos, auxiliavam na produção para a comercialização (relacionados à produção de leite e café na unidade familiar).

Alguns relatos expressaram as dificuldades envolvendo as mulheres em relação ao trabalho fora das unidades familiares: "[...] agora também as crianças estão pequenas; não tem como eu trabalhar (fora da unidade familiar) também, tem que esperar crescer mais! [...]" (ENTREVISTA 3); "De vez em quando apanhava café perto de casa, mas cuido do meu tio quando a minha mãe não pode. Aí não tem jeito de apanhar (café)!” (ENTREVISTA 11); “[...] já trabalhei apanhando café [...], mas deixei porque comecei a passar mal porque estava doente [...] agora só trabalho em casa mesmo!" (ENTREVISTA 14); E ainda:

Saí para trabalhar com ela (a filha) pequena, aqui não tem com quem deixar! Aí não tem serviço, se for para trabalhar tem que ir para a cidade. Aí é pior ainda [...] eu não tenho ninguém para cuidar dela para mim! (ENTREVISTA 13).

A constatação desta realidade relacionada às mulheres, que são inclusive as titulares preferenciais do programa e a maioria dos titulares entrevistados, se confirma quando comparada aos dados gerais do município analisados pelo IBGE a partir do Censo Demográfico (Instituto Brasileiro de Geografia e Estatística, 2010), que apontam que do total de homens de 16 anos ou mais economicamente ativos (ou 1689 indivíduos), aproximadamente $98 \%$ eram ocupados (ou 1665 indivíduos). Segundo a mesma fonte, das mulheres na mesma condição (823 indivíduos), 75\% eram ocupadas (618 indivíduos), confirmando a maior dificuldade das mulheres (Instituto Brasileiro de Geografia e Estatística, 2010).

Segundo Castilho e Silva \& Schneider (2015, p. 453), as mulheres "tendem a ter maior jornada doméstica [...] e que as mulheres com filhos pequenos podem ter dificuldades de conciliar os cuidados com as crianças e o trabalho quando não há creches públicas ou algum membro da família que possa fornecer esses cuidados".

Em relação às estratégias de diversificação dos meios de vida, Ellis $(1999$, p. 2) também afirma que o acesso a recursos e oportunidades para a diversificação dos meios de vida é diferente para homens e mulheres.

Segundo estudo de Mota et al. (2014, p. 198), que analisaram a relação entre a organização do trabalho familiar e a participação em programas de políticas públicas entre mulheres extrativistas, autodesignadas catadoras de mangaba e marisqueiras, no litoral do estado de Sergipe:

[...] diferente do PAA, que estimula a ação das mulheres extrativistas na coleta vegetal, o PBF está mais associado à sua presença na esfera privada, no qual as ações afetas à reprodução do grupo doméstico têm maior relevância em decorrência das condicionalidades do programa.

Segundo os autores, o Programa Bolsa Família reforça papéis tradicionais, mas, ao mesmo tempo, revaloriza o trabalho doméstico na esfera da reprodução e diminui a vulnerabilidade das beneficiadas em se submeter a trabalhos ofertados muitas vezes quase gratuitamente no mercado de trabalho. Moreira et al (2009) e Mota et al. (2014) afirmaram que a possibilidade de exercer os trabalhos domésticos (atribuída ao PBF) e de, paralelamente, participar de canais mais justos de comercialização dos produtos da atividade 
de extrativismo (atribuída ao PAA) e ainda a possibilidade de paralisação remunerada em determinados momentos (atribuída ao Seguro Desemprego do Pescador Artesanal), "conformam as condições mínimas de bem-estar material para uma qualidade de vida cidadã" (Mota et al., 2014, p. 199).

$\mathrm{Na}$ verdade, a realidade feminina não só constatada neste estudo, mas também em outros estudos e regiões, ressalta a importância do Programa Bolsa Família especialmente para as mulheres, dado o contexto restrito de acesso a outros recursos e oportunidades de diversificação dos meios de vida. A partir da função atribuída ao recurso monetário e sua importância na sociedade atual, pode-se dizer que o programa contribui para o alcance das liberdades e capacidades conceituadas por Sen (2000), uma vez que contribui para proporcionar maior liberdade de consumo para as mulheres.

No período de realização deste estudo, não foi declarada a comercialização de produtos de horta e pomar, cuja produção esteve presente nas unidades familiares analisadas. Durante a pesquisa, em relação à participação em políticas voltadas à população rural, em apenas um caso foi relatado o conhecimento sobre a possibilidade de elaboração de projetos para a produção e financiamentos das atividades rurais, o que provavelmente está relacionado a projeto de acesso a créditos para os agricultores familiares. Contudo, para resultados mais conclusivos é necessário maior aprofundamento de pesquisa em relação ao acesso às políticas de crédito por parte dos agricultores familiares beneficiados pelo Programa Bolsa Família.

O estudo de Mota et al. (2014, p. 202) concluiu "que a coexistência de políticas sociais e políticas agrícolas de fomento econômico tem repercussão altamente virtuosa [...]". Segundo Grisa \& Schneider (2014), o Programa Nacional de Fortalecimento da Agricultura Familiar (PRONAF) se constituiu na principal política agrícola para a agricultura familiar e tem contado com recursos crescentes. Contudo, segundo os autores, estudos apontam que o programa tem beneficiado principalmente as unidades familiares de produção "[...] em melhores condições socioeconômicas, localizadas nas regiões Sul e Sudeste, e promovido o cultivo de produtos competitivos no mercado internacional [...]".

Castilho e Silva (2014) afirmam que a não complementaridade entre o PRONAF e PBF esteve relacionada à maior vulnerabilidade dos beneficiados pelo $\mathrm{PBF}$, que os impede muitas vezes de acessar a política de crédito, apontando a falta de documentação, pouca disponibilidade de terra e acesso à informação, como fatores importantes neste processo.

Nesta pesquisa, no município de Luminárias, foi possível constatar apenas dois casos em que houve a participação no PAA por parte das famílias analisadas (beneficiadas pelo Programa Bolsa Família). Esta participação no PAA ocorreu entre 2010 e 2012, quando este programa estava ativo no município. A maior parte dos entrevistados não participou ou não tinha conhecimento sobre o Programa de Aquisição de Alimentos (PAA) e o Programa Nacional de Alimentação Escolar (PNAE). Esta evidência sugere que, provavelmente, os programas atingem, em geral, públicos distintos, ou seja, o público atingido pelo PBF não acessa ou acessou outras políticas voltadas para os agricultores familiares, porque ainda não apresentava organização social e produtiva necessária a tal acesso.

Em relação à organização formal da população rural, no período compreendido por esta pesquisa, existia no município analisado a Associação de Agricultores Familiares de Luminárias, que esteve envolvida nos processos de comercialização do Programa de Aquisição de Alimentos (PAA) e estava, no período compreendido pelo estudo, sem sede. Contudo, nenhuma entrevista mencionou a participação nesta organização.

O contexto de pobreza dos beneficiados do Programa Bolsa Família pode contemplar uma série de privações, como o não acesso a outras políticas. Quando a análise se refere ao contexto rural, essas políticas possuem, em geral, um viés agrícola e de produção. Assim, ao se projetar um incremento na organização da produção agrícola, com consequente retorno satisfatório de renda, é necessário pensar uma série de ações integradas que dinamizem as unidades familiares, proporcionem um rompimento com a histórica exclusão em relação às políticas agrícolas e de desenvolvimento rural e façam frente às limitações de acesso a informação e serviços, limitações para organização social da população rural mais vulnerabilizada. 
Vale destacar que não foi relatado nenhum investimento direto do recurso monetário, transferido pelo Programa Bolsa Família, em processos produtivos agrícolas ou de criação animal, nas unidades familiares visitadas. Isso pode ter relação com os valores transferidos, que não são suficientes para garantir o consumo familiar necessário e o investimento na produção agropecuária. Além disso, a frágil organização social pode inviabilizar a possibilidade de investimento no processo produtivo, com vistas à comercialização e retorno em renda. Em relação ao repasse realizado pelo programa, os relatos de pesquisa expressam: "Bom demais! Não é muito dinheiro, mas faz fartura" (ENTREVISTA 2); “O pouco que entra já ajuda, né?" (ENTREVISTA 4); "[...] O dinheiro que eu tô recebendo do Bolsa Família é pouco, mas esse pouco que eu estou recebendo ajuda e muito! A gente sabendo controlar [...]" (ENTREVISTA 13). Os relatos evidenciam o caráter de ajuda atribuído às transferências realizadas pelo programa.

O incremento na produção agrícola, seguida de comercialização, que representaria mais uma estratégia de diversificação da renda e, portanto, dos meios de vida das famílias, também fica condicionado a ações integradas que apontem para a capacitação e para produção e organização da população rural denominada pobre.

As limitações das unidades familiares, mais vulnerabilizadas, para estabelecer estratégias de diversificação de renda e, portanto, dos meios de vida convergem com a afirmação de Ellis (1999) de que embora se aceite que a diversificação de meios de vida é benéfica para as famílias pobres e que a diversificação de renda coloca-se como um fator importante neste processo, é necessário considerar que as unidades familiares em melhores condições são capazes de diversificar em mercados de trabalho mais favoráveis do que as famílias rurais pobres ${ }^{13}$. Certamente, esta situação tem relação com os recursos/ativos disponíveis aos pobres rurais que apontam para uma maior precariedade não só relacionada aos recursos financeiros, mas a outras privações de oportunidades e possibilidades de se qualificar, por exemplo.

Em relação à capacitação dos beneficiados, o que está vinculado com a disponibilidade dos recursos humanos constitutivos dos meios de vida, os dados da presente pesquisa identificaram a realização de cursos que já haviam sido oferecidos para os participantes do Programa Bolsa Família no município de Luminárias (Minas Gerais), como os do PRONATEC, SENAC e oferecidos pelo Centro de Referência de Assistência Social (CRAS), que incluíam: curso de informática, cuidadores de idosos e crianças, costura industrial, oficina de corte e costura industrial e operador de máquina, por exemplo. Contudo, estes cursos geralmente eram oferecidos na sede do município, em geral no período noturno, o que pode limitar a participação da população da zona rural em função das distâncias. Provavelmente em função disso, a realização dos cursos não foi muito citada nas entrevistas.

Em relação à exigência das condicionalidades em educação e saúde, entende-se que o cumprimento desta exigência pode ampliar as capacidades de gerações futuras e representar fator estruturante para possibilidades de diversificação dos meios de vida, possibilitando o rompimento ou minimização da pobreza. Contudo, Anthony Hall (2008) afirma que o aumento da demanda pelos serviços de educação e saúde não representa necessariamente a melhoria da sua qualidade. Hall (2012) alerta para o fato de que estimular a frequência escolar através do Bolsa Família pode ter um impacto limitado se a qualidade da educação for baixa e não houver os investimentos necessários para sua devida manutenção. Desta forma, a partir deste estudo não foi possível perceber os impactos sobre este aspecto de forma a analisar como e em que medida o acesso ao programa foi um fator com capacidade estruturante das possibilidades de diversificação a partir das condicionalidades. Para isso, seria necessária uma análise retrospectiva e de trajetória, considerando também os inúmeros fatores relacionados não só à frequência escolar, mas à qualidade de ensino, sua relação com os valores familiares, culturais, relações sociais, diretrizes políticas, entre outras.

\footnotetext{
${ }^{13}$ Extraído do original: It is widely agreed that a capability to diversify is beneficial for households at or below the poverty line. Having alternatives for income generation can make the difference between minimally viable livelihoods and destitution. However, diversification does not have an equalizing effect on rural incomes overall. Better-off families are typically able to diversify in more favorable labour markets than poor rural families (Ellis, 1999).
} 


\section{CONSIDERAÇÕES FINAIS}

A partir desta pesquisa, realizada na zona rural do município de Luminárias/MG, verificou-se que os recursos monetários provenientes do Programa Bolsa Família representaram contribuição fundamental para o atendimento de algumas necessidades básicas das famílias analisadas (como acesso a determinados itens da alimentação, do vestuário, entre outros), com relativa liberdade de consumo. Percebeu-se, ainda, que o consumo de alguns bens destinou-se a suprir parte das necessidades materiais, contribuindo para a melhoria da condição de vida dos beneficiados; mas também atendeu às necessidades sociais, o que contribui para a ampliação da inclusão/integração em espaços de sociabilidade, como a escola, postos de saúde e o comércio. A inserção ao comércio, na sede no município, se deu principalmente pelas vias do consumo. Destaca-se que em uma sociedade monetarizada, estas são condições fundamentais para a superação da pobreza, exercício de cidadania e acesso a outros direitos.

A estabilidade e a segurança de renda regular, principalmente para as mulheres, contribuíram para a minimização de vulnerabilidades e privações, ao mesmo tempo em que representaram a possibilidade de diversificação de renda e dos meios de vida em médio e longo prazos por meio de estratégias mais promissoras para as beneficiadas, o que depende de fatores relacionados ao contexto sociopolítico e econômico em que estão inseridas e de suas capacidades.

Se por um lado, a partir do acesso às políticas sociais é possível pensar o espaço rural como espaço de vida e trabalho, por outro lado, para que a população rural realmente desfrute de boas condições, tanto de vida quanto de trabalho, é necessário assumir o potencial do Programa Bolsa Família como fator estruturante de novas possibilidades de diversificação dos meios de vida e de renda. Mas também é necessário refletir sobre as limitaçães do programa em relação à integração com outras políticas e em relação à capacitação disponibilizada com vistas à geração de trabalho e renda.

Nesse sentido, as ações empreendidas pelo programa (transferência de renda e cumprimento das condicionalidades) devem ser acompanhadas por outras ações complementares que, no caso do ambiente rural, devem incluir o incentivo à produção agrícola e de criação animal, à comercialização e à organização social, acesso a créditos, oportunidades de trabalho e capacitações voltadas para as demandas rurais. Para aquelas localidades distantes de centros urbanos, determinadas capacitações promovidas devem considerar as dificuldades de deslocamento e a impossibilidade de utilização das capacidades adquiridas no próprio local. Neste contexto, questões mais amplas têm sido fundamentais, como o modelo de desenvolvimento rural que contemple sua diversidade e os arranjos e relações entre o rural e o urbano.

O Programa Bolsa Família contribui indiretamente para o alcance de direitos sociais básicos, como saúde e educação; contudo, é extremamente válida a análise de que o acesso aos serviços é fundamental, mas não garante a sua qualidade, que também é elemento fundamental para a estruturação de novas possibilidades de diversificação dos meios de vida. Estes são elementos para novas pesquisas e novas reflexões que poderão ampliar as discussões teóricas e empíricas em torno de políticas públicas e analisar seus efeitos ao longo do tempo.

\section{REFERÊNCIAS}

Barbosa, V. S., \& Paulo, M. A. L. (2012). O bolsa família e sua contribuição para o desenvolvimento local. In Anais do XV Encontro de Ciências Sociais do Norte e Nordeste E Pré-alas Brasil. Teresina: UFPI. Recuperado em 20 de julho de 2015, de http://www.sinteseeventos.com.br/ciso/anaisxvciso/resumos/GT20-44.pdf

Brasil. (1988, outubro 5). Constituição da República Federativa do Brasil de 1988. Diário Oficial [da] República Federativa do Brasil, Brasília. Recuperado em 1 de novembro de 2015, de http://www.planalto.gov.br/ccivil_03/constituicao/ConstituicaoCompilado.htm

Brasil. (2004, setembro 17). Decreto $n^{\circ}$ 5.209, de 17 de setembro de 2004. Regulamenta a Lei $n^{\circ} 10.836$, de 9 de janeiro de 2004, que cria o Programa Bolsa Família, e dá outras providências. Diário Oficial 
[da] República Federativa do Brasil, Brasília. Recuperado em 28 de abril de 2015, de http://www.planalto.gov.br/ccivil_03/_ato2004-2006/2004/decreto/d5209.htm

Brasil. Ministério da Cidadania. Secretaria de Avaliação e Gestão de Informações - SAGI. (2014). Relatório de informações sociais. RI Bolsa Família e Cadastro Único Luminárias (MG). Recuperado em 25 de novembro de 2014, de http://aplicacoes.mds.gov.br/sagi/RIv3/geral/relatorio.php\#Visão Geral

Brasil. Ministério da Cidadania. Secretaria de Avaliação e Gestão de Informações - SAGI. (2015). Panorama municipal segundo Censo Demográfico 2010. Recuperado em 19 de maio de 2015, de http://aplicacoes.mds.gov.br/sagi/ri/carrega_pdf.php?rel=panorama_municipal

Campello, T. (2013). Uma década derrubando mitos e superando expectativas. In T. Campello \& M. C. Neri (Eds.), Programa Bolsa Família: uma década de inclusão e cidadania. Brasília: IPEA.

Castilho \& Silva, C. B. (2014). O Programa Bolsa Família no meio rural: um caminho ao desenvolvimento no Rio Grande do Sul? (Tese de doutorado). Universidade Federal do Rio Grande do Sul, Porto Alegre.

Castilho e Silva, C. B., \& Schneider, S. (2015). Pobreza rural e o Programa Bolsa família: desafios para o desenvolvimento rural no Brasil. In C. Grisa \& S. Schneider (Eds.), Políticas públicas de desenvolvimento rural no Brasil. Porto Alegre: UFRGS. Recuperado em 1 de junho de 2015, de $<$ http://lemate.paginas.ufsc.br/files/2015/06/Livro_Politicas_publicas.pdf

Craveiro, C. B. A., \& Ximenes, D. A. (2013). Dez anos do Programa Bolsa Família: desafios e perspectivas para a universalização da educação básica no Brasil. In T. Campello \& M. C. Neri (Eds.), Programa Bolsa Família: uma década de inclusão e cidadania. Brasília: IPEA.

Ellis, F. (1998). Household strategies and rural livelihood diversification. The Journal of Development Studies, 35(1), 1-38. http://dx.doi.org/10.1080/00220389808422553

Ellis, F. (1999). Rural livelihood diversity in developing countries: evidence and policy implications (No. 40). Overseas Development Institute. Recuperado em 27 de março de 2015, de http://www.odi.org/sites/odi.org.uk/files/odi-assets/publications-opinion-files/2881.pdf

Grisa, C., \& Schneider, S. (2015). Apresentação. In C. Grisa \& S. Schneider (Eds.), Políticas públicas de desenvolvimento rural no Brasil. Porto Alegre: UFRGS. Recuperado em 1 de junho de 2015, de http://lemate.paginas.ufsc.br/files/2015/06/Livro_Politicas_publicas.pdf

Grisa, C., \& Schneider, S. (2014). Três Gerações de Políticas Públicas para a Agricultura Familiar e Formas de Interação entre Sociedade e Estado no Brasil. Revista de Economia e Sociologia Rural, 52(Suppl.1), 125-146. http://dx.doi.org/10.1590/S0103-20032014000600007

Hall, A. (2008). Brazil's Bolsa Familia: a double-edged sword? Development and Change, 39(5), 799-822.

Hall, A. (2012). The last shall be first: political dimensions of conditional cash transfers in Brazil. Journal of Policy Practice, 11(1-2), 25-41.

Höfling, E. M. (2001). Estado e políticas (públicas) sociais. Cadernos CEDES, 21(55), 30-41. http://dx.doi.org/10.1590/S0101-32622001000300003

Instituto Brasileiro de Geografia e Estatística - IBGE. (2006). Censo agropecuário 2006. Rio de Janeiro: IBGE. Recuperado em 20 de abril de 2014, de http://www.cidades.ibge.gov.br/xtras/temas.php?lang=\&codmun=313870\&idtema=3\&search=mina s-gerais | luminarias |censo-agropecuario-2006

Instituto Brasileiro de Geografia e Estatística - IBGE. (2010). Censo demográfico 2010. Rio de Janeiro: IBGE. Recuperado em 20 de abril de 2014, de http://www.cidades.ibge.gov.br/xtras/perfil.php?lang=\&codmun=313870\&search=minasgerais | luminarias|infograficos:-informacoes-completas

Jannuzzi, P. M., \& Pinto, A. R. (2013). Bolsa Família e seus impactos nas condições de vida da população brasileira: uma síntese dos principais achados da pesquisa de Avaliação de Impactos do Bolsa Família II. In T. Campello \& M. C. Neri (Eds.), Programa Bolsa Família: uma década de inclusão e cidadania. Brasília: IPEA.

Jesus, A. C. S. (2011). O Programa Bolsa Família: seus impactos econômicos, socioculturais e políticos em pequenos e médios municípios do Rio Grande do Nortel Brasil (Tese de doutorado). Programa de Pósgraduação em Políticas Públicas, Universidade Federal do Maranhão, São Luís.

Leroy, R. S. D., Ferreira, M. A. M., Moreira, N. C. M., \& Silva, E. A. (2014). Mobilidade social e empoderamento: a percepção das mulheres beneficiárias do programa Bolsa Família em Minas Gerais. Revista do Serviço Público, 62(4), 449-465. http://dx.doi.org/10.21874/rsp.v62i4.82 
Lui, G. H., \& Molina, S. M. G. (2013). Benefícios sociais e transição de modos de vida rural: uma análise do Bolsa Família e da aposentadoria rural entre pequenos produtores na Amazônia. Política \& Trabalho Revista de Ciências Sociais, 38, 137-155.

Mesquita, C. S. (2007). O Programa Bolsa Família: uma análise de seu impacto e significado social (Dissertação de mestrado). Programa de Pós-graduação em Política Social, Universidade de Brasília, Brasília.

Moreira, R. C., Braga, M. J., Carvalho, F. M. A., Lima, J. R. F., \& Silva, J. M. A. (2009). Políticas públicas, distribuição de renda e pobreza no meio rural brasileiro no período de 1995 a 2005. Revista de Economia e Sociologia Rural, 47(4), 919. http://dx.doi.org/10.1590/S0103-20032009000400006

Morton, G. D. (2013). Acesso à permanência: diferenças econômicas e práticas de gênero em domicílios que recebem Bolsa Família no sertão baiano. Política \& Trabalho Revista de Ciências Sociais, 38, 4367.

Mota, D. M., Schmitz, H., Silva Júnior, J. F., \& Rodrigues, R. F. A. (2014). O trabalho familiar extrativista sob a influência de políticas públicas. Revista de Economia e Sociologia Rural, 52(Suppl.1), 189-204. http://dx.doi.org/10.1590/S0103-20032014000600010

Neder, H., Alves Filho, N., \& Souza, S. (2015). Acesso à renda e inflação de preços de alimentos no Brasil: análise dos efeitos do programa Bolsa Família. Revista de Economia e Sociologia Rural, 53(1), 51-70. http://dx.doi.org/10.1590/1234-56781806-9479005301003

Niederle, P. A., \& Grisa, C. (2008). Diversificação dos meios de vida e acesso a atores e ativos: uma abordagem sobre a dinâmica de desenvolvimento local da agricultura familiar. Cuadernos de Desarrollo Rural, 5(61), 41-69. Recuperado em 7 de junho de 2015, de http://www.redalyc.org/articulo.oa?id=11713138002

Paiva, L. H., Falcão, T., \& Bartholo, L. (2013). Do Bolsa Família ao Brasil Sem Miséria: um resumo do percurso brasileiro recente na busca da superação da pobreza extrema. In T. Campello \& M. C. Neri (Eds.), Programa Bolsa Família: uma década de inclusão e cidadania. Brasília: IPEA.

Pereira, P. A. P. (2009).Discussões conceituais sobre política social como política pública e direito à cidadania. In I. Boschetti, E. R. Behring, S. M. M. Santos \& R. C. T. Mioto (Eds.), Política Social no Capitalismo: tendências contemporâneas (2. ed.). São Paulo: Cortez.

Perondi, M. A., \& Schneider, S. (2012). Bases teóricas da abordagem de diversificação dos meios de vida. Revista do Desenvolvimento Regional, 17(2), 117-135. Recuperado em 22 de agosto de 2015, de https://online.unisc.br/seer/index.php/redes/article/view/2032/2175

Pires, F. F., \& Jardim, G. A. S. (2014). Geração Bolsa Família: escolarização, trabalho infantil e consumo na casa sertaneja (Catingueira/PB). Revista Brasileira de Ciências Sociais, 29(85), 99-112. http://dx.doi.org/10.1590/S0102-69092014000200007

Rego, W. D. L., \& Pinzani, A. (2013). Liberdade, dinheiro e autonomia: o caso da Bolsa Família. Revista de Ciencias Sociales, 38, 21-42. Recuperado em 21 de maio de 2015, de http://periodicos.ufpb.br/ojs/index.php/politicaetrabalho/article/view/15029/9376

Santos, C. R. B., \& Magalhães, R. (2012). Pobreza e Política Social: a implementação de programas complementares do Programa Bolsa Família. Ciência \& Saúde Coletiva, 17(5), 1215-1224. http://dx.doi.org/10.1590/S1413-81232012000500015

Sant'Ana, S. M. (2014). A perspectiva brasileira sobre a pobreza: um estudo de caso do Programa Bolsa Família. Revista do Serviço Público, 58(1), 5-35. http://dx.doi.org/10.21874/rsp.v58i1.161

Secchi, L. (2010). Políticas públicas: conceitos, esquemas de análise, casos práticos. São Paulo: Cengage Learning.

Sen, A. (2000). Desenvolvimento como liberdade (Introdução, Cap. 1, Cap. 2). São Paulo: Companhia das Letras.

Soares, S., \& Sátyro, N. (2009). O Programa Bolsa Família: desenho institucional, impactos e possibilidades futuras (Texto para Discussão, No. 1424). Brasília: IPEA. Recuperado em 5 de agosto de 2014, de http://repositorio.ipea.gov.br/bitstream/11058/2598/1/TD_1424.pdf 